\title{
Studying the Impression of Saudi People towards Current Social Changes
}

\author{
Hawra Rabaan \\ Indiana University, IUPUI \\ Human-Centered Computing \\ 535 W Michigan Street \\ Indianapolis, IN 46202 USA \\ hrabaan@iu.edu

\section{Sunandan Chkraborty} \\ Indiana University, IUPUI \\ Data Science \\ 535 W Michigan Street \\ Indianapolis, IN 46202 USA \\ sunchak@iu.edu

\section{Alyson L. Young} \\ Indiana University, IUPUI \\ Human-Centered Computing \\ 535 W Michigan Street \\ Indianapolis, IN 46202 USA \\ youngalys@iupui.edu
}

Permission to make digital or hard copies of part or all of this work for personal or classroom use is granted without fee provided that copies are not made or distributed for profit or commercial advantage and that copies bear this notice and the full citation on the first page. Copyrights for third-party components of this work must be honored. For all other uses, contact the owner/author(s). CSCW '18 Companion, November 3-7, 2018, Jersey City, NJ, USA

(c) 2018 Copyright is held by the owner/author(s)

\begin{abstract}
In this work-in-progress paper, we examine how the campaign to end the guardianship law in Saudi Arabia is being discussed and debated on social media.

Through a content analysis of tweets, we first identify those with either a positive or negative sentiment towards ending the law and then we identify topical themes across these sentiment categories. We found polarizing responses with individuals either calling for the end of the law or those opposing its end on religious or moral grounds. This analysis provides a basis for building a model to automatically code tweets to increase the accuracy of Arabic text prediction. This will allow us to answer new questions about the dataset and inform the design of ICTs.
\end{abstract}

\section{Author Keywords}

Sentiment Analysis; Data Mining; Social Computing; Arab HCI.

\section{Introduction}

Saudi Arabia has been going through unforeseeable rapid changes in the past two years with women at the forefront of these changes. One notable change is the recent ban lifted on women driving. On the ground, a resilient movement is calling to end the guardianship law. Guardians are male relatives systematically 
assigned to related females to provide protection by law [1]. This law, however, enables the exploitation of women, giving guardians absolute control over many aspects of her life, including education, travel, health, and career. Since 2011, a campaign has been waging to end the guardianship law. Initially intended to last 365 days, it has since exceeded 720 days.

\begin{tabular}{|c|c|c|c|c|}
\hline & \multicolumn{3}{|c|}{ Coder 2} \\
\hline & & Positive & Neutral & Negative \\
\hline \multirow{3}{*}{ نे } & Positive & 425 & 10 & 21 \\
\hline & Neutral & 24 & 25 & 24 \\
\hline & Negative & 6 & 4 & 460 \\
\hline
\end{tabular}

Table.1: Inter-rater Reliability Computation
In this work-in-progress, we seek to understand how the rapid socio-political changes in Saudi Arabia are being discussed on social media, with a particular focus on ending the guardianship law. Our study found polarizing responses with individuals' either calling for the end of the law completely or those opposing its end on religious or political grounds.

\section{Related Work}

A body of work is starting to emerge on $\mathrm{HCI}$ in the Arab context. This work has focused on privacy dimensions and concerns [4], self-identity management $[5,6]$, and safety [7]. One area of particular relevance to this study is the ways that social media were used and mobilized during the Arab Spring [2][3]. While not directly related to the Saudi context, several movements within this part of the world have arisen as result. We extend the research in this area to understand how social media is being leveraged to support and discuss the movement in Saudi Arabia to modify or abolish the guardianship law. This research is particularly relevant because it focuses on women's rights and the Saudi conflicting evidence with some Saudi women perceiving the law to be positive with others feeling it restricts their legal capacity [1].

\section{Methods}

Between November 27, 2017 and June 22, 2018, we queried the Twitter streaming API using the hashtags "Saudi women demand ending the guardianship" (official campaign), "Saudi Women proud of our family's guardianship" (counter campaign), and "ending the guardianship". ${ }^{1}$ Only those tweets from within Saudi Arabia and in Arabic were captured, allowing us to examine discussions happening on the ground and reduce outsider bias. This resulted in 13,534 tweets.

Two native Arabic speakers manually coded 999 randomly selected tweets for positive (1), negative $(-1)$, and neutral $(0)$, with a $91 \%$ agreement (Table 1 ). Positive tweets were those supporting the end of the guardianship law, negative tweets were against ending the law, and neutral tweets either had no direct impact on the issue or contained both positive and negative sentiments. Once organized into these sentiment categories, we inductively coded them for topical themes. Example tweets were translated to English.

\section{Findings}

\section{Positive Responses}

Forty-two percent of tweets ( $n=425$ ) were positive, focusing on three themes. The first theme focused on providing explanations of the campaign's purpose and spreading awareness. We found that a number of the tweets included videos and/or text that outlined the campaign demands, reasons for these demands, and their relationship to Islamic law and moral reasoning. For example, one individual shared the purpose of the campaign is to demand the end of the guardianship law

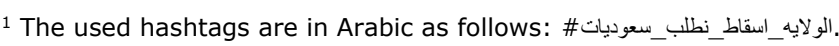

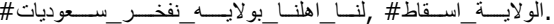


to "empower women without a guardian ... to ensure that all women in the country have equal rights." The reasoning behind this was so "that women do not fall prey to the coincidence of the 'guardian' where if he's reasonable he'd treat her fairly, \& if he wasn't he'd ruin her life!!"

The second theme we identified focused on a call to action to modify or eliminate the law to ensure better protection of Saudi women. For example, one individual called for a change to current policies: "Violence reports should be handled by the police and be treated as a major crime, like the initiation of murder, with firm intervention and the imprisonment of the violator..."

In other cases, individuals called for the abolition of the law based on moral arguments: "... the guardianship document is a slavery document ... it restricts the freedom of women in everything..."

The final theme focused on attempts to debunk religious and moral accusations. For instance, one individual contended the prevailing belief that the law is part of the religious moral doctrine is incorrect:

"..ending the guardianship law does not mean your disintegration and departure from values and discarding your family, it is a right of yours guaranteed by Sharia".

\section{Negative Responses}

Forty-six percent of tweets $(n=460)$ were negative, focusing on five themes. The first theme centered on reductive arguments; that violence occurs even in the absence of a guardian and therefore the law is not to blame. In particular, individuals drew comparisons to the West: "Violence is not due to customs and traditions \& the West is proof to that. The main reason is the lack of faith, bad morals, \& the guardian disrespecting women based on his upbringing"

The second theme revolved around misunderstandings about the campaign's goals and purpose. For instance, one individual questioned what harm the law has done, referring to women's ability pursue different professions: "...What is the ambition of some Saudi women by ending the guardianship? She's a teacher, journalist, nurse, doctor, businesswoman [...]. What's the purpose of traveling alone?"

The third theme focused on denial of campaign legitimacy with individuals arguing that those seeking to end the law have ulterior motives: "Ending the guardianship is a political, social, economic and moral war. Colonialism kills beliefs, religions and societies from within without firing a single shot. ..."

The fourth theme focused on the continuum fallacy where individuals argued ending the law would lead to other consequences: "We ask the security forces to investigate those who demanded the demolishment of the guardianship \& their real goals behind these claims ...Today they want to drop their fathers \& tomorrow they will demand the removal of the king!"

The final theme deals with misogyny couched in religious doctrine, whereby the natural order dictates that men assert their mastery over women. In the following tweet, the author makes reference to an interpretation of the Qur'an by an influential Islamic scholar that women must obey men: "Allah says (But the men have a degree over them" [...] How do you 
demand equality between the prisoner and master? \& women's job is to obey, who will they obey when guardianship ends? A man is more intelligent and has wiser insight that is why he is the guardian"

\section{Discussion \& Future Work}

Our study shows that there are strong positions on either side of the debate. Those who argued for its abolishment did so on the grounds of empowering women and increasing their autonomy. By contrast, individuals against the abolishment objected on moral and religious grounds. In some cases, objections were based on self-interest, misogyny, and misinformation.

A limitation of our study is that our use of simple binaries to account for positive and negative responses did not account for variance in context and perspective. In future work, we will code the tweets at a finer level of granularity to ensure we capture this variance.

This study provides a basis for creating a machinelearning model to automatically code tweets. This will help increase the accuracy of Arabic text prediction. Further, once we have a robust model, it will allow us to answer more questions (e.g. is a majority or a minority demanding the change? Is the acceptance of social change dependent on higher decision-making or is it a fixed ideology? Does gender, age, social ranking, account type, or location play a role in the discussion?).

\section{References}

1. Rakan Alharbi. 2015. Guardianship Law in Saudi Arabia and Its Effects on Women's Rights. Working Paper: DOI: 10.13140/RG.2.2.34304.12801.

2. Karim Hamza. 2014. Social media as a tool for social movements in Arab spring countries. In
Proceedings of the 8th International Conference on Theory and Practice of Electronic Governance (ICEGOV'14), 71-74.

3. Volker Wulf, Kaoru Misaki, Meryem Atam, David Randall and Markus Rohde. 2013. On the ground in Sidi Bouzid: Investigating social media use during the Tunisian revolution. In Proceedings of the 2013 ACM Conference on Computer -Supported Cooperative Work and Social Computing (CSCW'13), 1409-1418.

4. Norah Abokhodair and Sarah Vieweg. Privacy \& Social Media in the Context of the Arab Gulf. In Proceedings of the 2016 ACM Conference on Designing Interactive Systems (DIS'16), 672-683.

5. Sarah Vieweg and Adam Hodges. Surveillance \& Modesty on Social Media: How Qataris Navigate Modernity and Maintain Tradition. In Proceedings of the 19th ACM Conference on Computer-Supported Cooperative Work \& Social Computing (CSCW'16), 527-538

6. Hashem Abdullah Almakrami. 2015. Online SelfDisclosure Across Cultures: A Study of Facebook Use in Saudi Arabia and Australia. PhD

Dissertation. Queensland University of Technology, Queensland, Australia.

7. Chelsea Young. 2017. HarassMap: Using Crowdsourced Data to Map Sexual Harassment in Egypt. Technology Innovation Management Review 4, 3: 7-13. 